Methods: A case study was performed in one of the most affected municipalities- Nova Friburgo. Data related to types of medical complaints in local emergency services, one week before and after the disaster was collected. Victims, health professionals and public health managers were interviewed. The requirements for physical rehabilitation and the responsiveness of health services in the disaster's recovery period were explored. Simple frequency measures were applied for quantitative data and the content of interviews was analyzed.

Results: Twelve affected people were interviewed, nine women (average 47 years old) and three men (average 43 years old). Only one women had private health care insurance. Seven women and three men had jobs before the disaster, $40 \%$ of them were able to keep working after the disaster. The proportion of traumatic complaints in the emergency municipal service tripled in the week after the disaster. However, there was no increase in the demand for rehabilitation services in the municipality. Possible explanations arise from the analysis of interviews: lack of knowledge about physical rehabilitation possibilities, lack of confidence concerning the public health services, prioritization of other activities related to life maintenance (eg. overcome losses and family care) and misconception of patient complaints by health professionals, hampering the continuity of care.

Conclusion: The demand for rehabilitation was suppressed after the disaster, being of utmost importance to actively seek the victims out.

Prehosp Disaster Med 2017;32(Suppl. 1):s108-s109

doi:10.1017/S1049023X17003132

\section{Disaster Complexity: South Pacific Origins of the Blizzard of 2016}

James M. Shultz

Deep Center, University of Miami Miller School of Medicine, Miami/ FL/United States of America

Study/Objective: Apply complexity science to a disaster case study.

Background: The Blizzard of 2016 produced blizzard conditions and heavy snowfall throughout the Mid-Atlantic and Northeast United States during January 22-24, 2016. This Category 4 ("crippling") nor'easter created significant human impact due to its passage over densely-populated coastal "megalopolises", extending from Washington D.C. to Boston. Methods: A multidisciplinary team was assembled to review this storm from a complexity sciences vantage. The blizzard was distinguished by its dynamic, "globally-networked" risk landscape, a hallmark of complexity. Investigators explored how factors related to climate change, including record-setting global temperatures and a powerful El Niño, ultimately contributed to the season's strongest winter storm.

Results: The Blizzard of 2016 was a natural hydrometeorological disaster; combining elements of winter storm, nor'easter, blizzard, and coastal flood; that disrupted transportation and infrastructure for millions. With snow depths exceeding 3 feet in some areas, the blizzard covered an estimated 434 thousand square miles and impacted more than 100 million people. The antecedent climate events that led to the blizzard included an explosive, thunderstorm-generating interaction between the east-to-west migrating MaddenJulian Oscillation (MJO), emerging from the Indian Ocean, as it encountered peak ocean temperatures associated with an extremely strong 2015/2016 El Niño Southern Oscillation (ENSO). This took place in the tropical Pacific Ocean, just north of American Samoa, in the vicinity of the equator where it intersects with the International Date Line. This destabilizing MJO-ENSO interaction affected the jet stream and set in motion a cascade of atmospheric effects, that ultimately influenced the development of a powerful blizzard several weeks later and 7,000 miles $(11,000 \mathrm{~km})$ away.

Conclusion: From a disaster complexity point of view, the Blizzard of 2016 reveals the intricate interconnections among weather systems worldwide, and illustrates how natural and anthropogenic (eg. climate change) phenomena interact to produce far-ranging consequences.

Prehosp Disaster Med 2017;32(Suppl. 1):s109

doi:10.1017/S1049023X17003144

\section{A Framework for Analyzing Performance Under Pressure in Diverse Healthcare Settings in Ecuador \\ Alicia Zavala Calahorrano, David Plummer, Gary E. Day, Anita Bamfore-Wade}

Griffith University, The Gold Coast/QLD/Australia

Study/Objective: To better understand the performance of health workers under pressure.

Background: This paper addresses a challenging landscape for health care professionals, and endeavours to analyze the healthcare system at a national level, and how it has adapted to the many challenges of both internal and external conditions. I have undertaken complex and extensive research to identify the factors that influence the responses of health professionals in diverse and changing scenarios, so as to examine their performance under extreme crisis situations.

Methods: Forty-five detailed interviews with key professionals (doctors, nurses, paramedics) were undertaken in diverse locations in Ecuador. Participants described high pressure scenarios including: natural disasters, emergency departments, large and small facilities, intensive care and operating theaters. Grounded theory was used to develop models to better understand performance under pressure.

Results: An 'emic' approach was used to understand 'pressure': namely, participants described scenarios where they personally experienced 'pressure'. Broad interacting classes of factors contributing to 'pressure' were identified. Using dramaturgical analysis, we developed a 'performative matrix' that helped deepen our understanding of performance under pressure as a dynamic, collectively-determined social phenomenon shaped by (1) facilities and systems (staging, props); (2) teams and personnel (roles, actors), and (3) case complexity (plots, storylines). Explanatory frameworks to emerge included dramaturgical, processual and evolutionary models.

Conclusion: Rather than capturing a static view of individuals and outcomes, performance is modeled as a complex unfolding collective drama. Using dramaturgical, processual and evolutionary 